\title{
PRODUCT AND PROCESS DEVELOPMENT INTENSITY IN PROCESS INDUSTRY: A CONCEPTUAL AND EMPIRICAL ANALYSIS OF THE ALLOCATION OF COMPANY RESOURCES FOR THE DEVELOPMENT OF PROCESS TECHNOLOGY
}

\author{
THOMAS LAGER \\ Department of Business Administration and Social Sciences \\ Division of Industrial Organisation \\ Luleå University of Technology \\ SE-97187 Luleå, Sweden \\ Thomas.Lager@ies.luth.se
}

Received 24 May 2001

Revised 4 July 2002

Accepted 16 July 2002

\begin{abstract}
In Process Industry, process development traditionally takes a large part of the company's total development efforts, but has nevertheless not received much attention in academic studies. As a part of a larger research project concerning process development in Process Industry, the allocation of company resources to $\mathrm{R} \& \mathrm{D}$, and to process development in particular, has been investigated in an exploratory survey to R\&D managers in European Process Industry (Mining \& Mineral Industry, Food \& Beverage Industry, Pulp \& Paper Industry, Chemical Industry, Basic Metal Industry, and Other Process Industry). The results show that of the total resources for R\&D, $40 \%$ was allocated to process development, and over $60 \%$ of the companies expected this figure to increase in the future. This figure not only shows the future importance of process development, but also indicates that the importance of product development in this group of companies is at present still rated higher than process development. The results from the study do not fit the most widely used theoretical models, and it is concluded that there is a need for better models with more explanatory power. The new concepts of product and process development intensity are introduced. The product and process development intensities can be looked upon as aggregated measures of individual development efforts by a company, and it is thus argued that they are of overall company strategic importance.
\end{abstract}

Keywords: Process Industry; process technology; process development; product development; innovation; product development intensity; process development intensity. 


\section{Balancing Company Resources for Product and Process Development - An Issue of Strategic Importance?}

Is the development of new process technology still a worthwhile undertaking, when the object nowadays is often to reduce the company's own share of production in the overall "supply chain"? Is production a "necessary evil", as Skinner provocatively put it in his praise of a process development strategy (Skinner, 1992)? How important is company process development in Process Industry now and in the future, and what is an appropriate distribution of R\&D resources between product development and process development? Although these questions are certainly not easy to answer, they have to be addressed by top management, and in particular by the director of R\&D or production, in making strategic decisions for the future, or at least in the development of the company's annual budget.

Customer orientation and improvement of company product development capability have been matters of concern in Process Industry for several years, but what about process development? Do the often short-term perspectives of shareholders, analysts and company top management allow too little resources for process development, because they are afraid that it will take too long and commit them to heavy capital outlay in the future? In Skinner's previously cited article comparing Process Industry with "non-process industry" he asks: "What can be learned from the process industries, where process innovation seems to be a way of life?" The question is whether process development still is and should be a way of life and an important area of R\&D in Process Industry.

If we assume that the importance of company process development is, or should be, reflected in the process development share of total annual expenditures on $\mathrm{R} \& \mathrm{D}$, and bear in mind that the development of products and processes often takes the lion's share of all R\&D resources in Process Industry, the balance between product and process development could be an important and strategic issue for top management. How important process development is, and consequently how much of company $\mathrm{R} \& \mathrm{D}$ resources is allocated to process development in Process Industry now and in the future, is the main research question for the empirical part of this study. Another purpose is to review existing theoretical models and to discuss, and possibly improve, concepts related to this area.

The foregoing questions were put in an exploratory survey to R\&D managers in European Process Industry as a part of a larger research project concerning the development of process technology in Process Industry. Before the results from the survey are presented, present concepts and models for product and process development in Process Industry will be discussed and the new concepts of "product and process development intensity" will be introduced. 


\section{Allocation of Resources for Product and Process Development in Process Industry - A Literature Review and a Conceptual Development}

\section{An introduction to product and process development in Process Industry}

One characteristic feature of significant importance with regard to product and process development in Process Industry is the complex production chain. The production chain, starting with raw materials, often includes intermediate deliveries of other finished products before final production and delivery of the end product to the customer. The production chain may include a number of large or small production plants, sometimes operated and owned by different companies, sometimes fully integrated in a long production chain within an industrial group or conglomerate. Each production plant may include several separate production processes that are likewise connected in a chain structure, illustrated in Fig. 1. Each of those individual processes often also includes several unit operations, with certain key operational equipment. Successful development of new products and new processes depends to a high degree on an understanding of this total chain structure (Tottie \& Lager, 1995). The impact that development activities have on company overall performance is likely to be associated with how much of this production chain is involved in the development of new products and processes. A reduction of the number of process steps might here be a good indicator of what can be regarded as major process improvements (Utterback, 1994).

\section{The complex production chain}

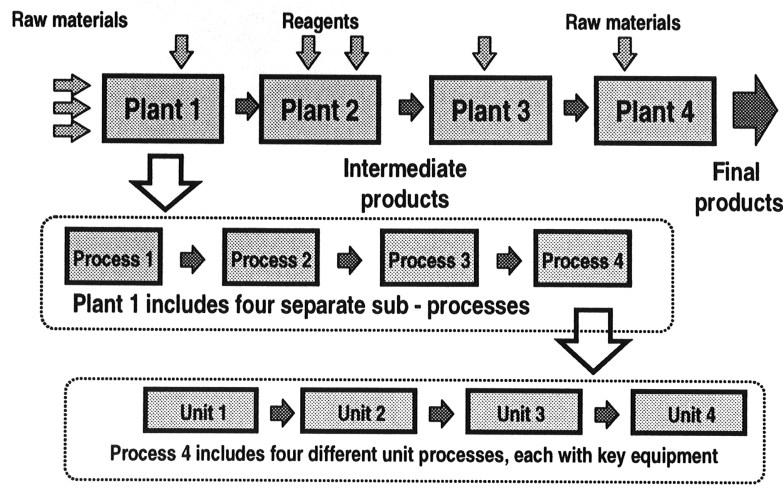

Fig. 1. A schematic model of the production process in Process Industry. A production chain in Process Industry is sometimes as complex as in other Manufacturing Industry. 
Focusing on the production process and process technology characteristics presented above, the following intensional type of definition of Process Industry, which was developed and used in this study, characterises this industry in a descriptive manner:

"Process Industry is Production Industry using (raw) materials to manufacture non-assembled products in a production process where the (raw) materials are processed in a production plant where different unit operations often take place in a fluid form and the different processes are connected in a continuous flow."

The above definition was further developed into an extensional definition that was used to classify different categories of Process Industry, see further Appendix.

Numerous articles have been published advocating the importance of product development in process industry (Balachandra \& Friar, 1997; Chronéer, 1999; Cobbenhagen et al., 1990; Cooper \& Kleinschmidt, 1995; Hutcheson et al., 1996; Linn, 1984). The importance of process development, not only as a costcutting tool but also as a way to speed up product development, is discussed by Gold (1987) in an article whose conclusions stress the importance of portfolio balancing of the total company R\&D programme. Improvement of R\&D efficiency is highlighted in a discussion of the need to restructure Japanese Chemical Industry, and cost reduction through technological innovation and improvement of the manufacturing processes is put at the top of the list in the search for better strategic resource allocations (Yoshida, 1998). In an extensive study of pharmaceutical industry, Pisano concludes that although product development is still much more important than process development in that industry, the production process for drugs is growing more complicated. Starting necessary process development too late can delay the market introduction of a new drug and reduce the potential profit before generic drugs are produced (Pisano, 1997). The above reflections might be generalised to other sectors of Process Industry, highlighting the importance of process development activities in reducing "time to market" for product development and as a cost cutting tool, but also their mutual dependence.

The organisational affiliation of process development and its influence on the performance of the development processes has not been studied to a great extent. The need to make old departmental-type organisations obsolete and shift to more transfunctional and flexible organisations in the future is often advocated. In a study of process development in pharmaceutical industry, Pisano identify two organisational models. In the specialised model, process research (belonging to 
$\mathrm{R} \& \mathrm{D})$ is separated from process development (belonging to production). In the integrated model, all process research and development is integrated in one function including manufacturing start-up. The performance of these different organisation models, however, shows an ambiguous picture (Pisano, 1997). A more unusual but very interesting option for new plants and newly formed companies, presented by Leonard-Barton (1992), is the complete integration of all $R \& D$ and production. The results from a recent study of success factors for process development show that success factors for incremental process development are quite different from those for more innovative process development, indicating an advantage of having organisational affiliation to both production and R\&D (Lager \& Hörte, 2002).

Before discussing the existing models for the mutual relationship between product and process development in Process Industry in more detail, let first scrutinise the often used but seldom defined concepts of product and process development.

\section{The need for a better distinction between product and process development in Process Industry}

The question comes down to whether a distinction between product and process development should be made, and if so, how. Defining process development in Process Industry must be done in relation to something, which in this case is the product development.

This may not be the case in Other Manufacturing Industry, where the development of production technology by its nature is not necessarily related to product development. Development of a new product in Process Industry is often related to the finding of an improved process, whereas in Other Manufacturing Industry a new product can be developed in the design office and the question of manufacturing the product can (but of course should not) be left until later. If the current assumption is the need to distinguish between product and process development, how can it be done? The concern here is the discriminating power of such a definition and its usability in Process Industry.

Going through the literature on product and process development in Process Industry, one can seldom find any definitions of the concepts. It sometimes seems as if the authors have some sort of self-evident and intuitive definitions that they do not consider it necessary to spell out explicitly. The definition presented by OECD in the "Oslo Manual" makes a clear distinction between product and process development, but notes that the distinction is sometimes difficult to make 
in some different types of industry (OECD, 1997). The difference between product development and production development may be obvious in Other Manufacturing Industry, but not in Process Industry. Although product and process development in Process Industry can sometimes be considered as two sides of the same coin - product development is often development work in a laboratory or pilot plant - the lack of distinction often creates confusion both in the operational performance of industrial $R \& D$ and in academic research.

A definition suited to process industry was thus developed and was further used in this study and presented to the respondents. To distinguish between the two terms, "process development" is defined in this study as development driven by internal production objectives. Such objectives may be reduction of production costs, higher production yields, improvement of production volumes and product recoveries, environment-friendly production, etc. In many sectors of Process Industry, process development work is mainly prompted by the needs of production (internal customers). Correspondingly, "product development" is defined as development driven by a desire to improve the properties and performance of finished products, even if it is practical development work in a laboratory. Objectives of product development may be to improve product properties, improve product quality (uniformity of composition), to develop environment-friendly products, etc.

The main difference (apart from the different objectives and customers for the development work) compared to the definition presented by OECD is that the inclusion of all development work with the sole object of improving product properties is clearly included in the product development category even though the work involves developing a better production process. The definition presented here is similar in its parts and its intent to others, e.g. one used in a publication on the Petrochemical Industry (Stobaugh, 1988). A combination of the two activities in a project is possible, but it is important to clarify the two different customers and objectives.

A process development project can thus give opportunities for product development, just as the development of new products can be combined with process development and cost reduction in the production process. The need to integrate product development activities and development of new or improved process technology for manufacturing has also been stressed by Pisano (1997). Not only do product and process development interact, but the relative importance of the two categories of development may differ for different companies in different business environments. The discussion of the most influential theoretical model (maybe not in industry but in academia) of the relation between product and process development will be following this section. 


\section{The relationship between product and process development in Process Industry - The Utterback \& Abernathy models revisited}

In 1975, Utterback and Abernathy presented a dynamic model of process and product innovation, where they related the rate of innovation in industry to its stage of development over time. The model was tested with empirical evidence from a previous study (Myers \& Marquis, 1969). The original model was later discussed and further developed into a slightly different form but with no further empirical evidence (Utterback, 1994). As a complement to this further developed model, new "waves" of innovation are sometimes also included when later stages in industry development have been reached. The original model has also been further developed in that a distinction is made between industries that manufacture "assembled products" and those that manufacture "non-assembled products", see Fig. 2 and the model for industries making "non-assembled products".

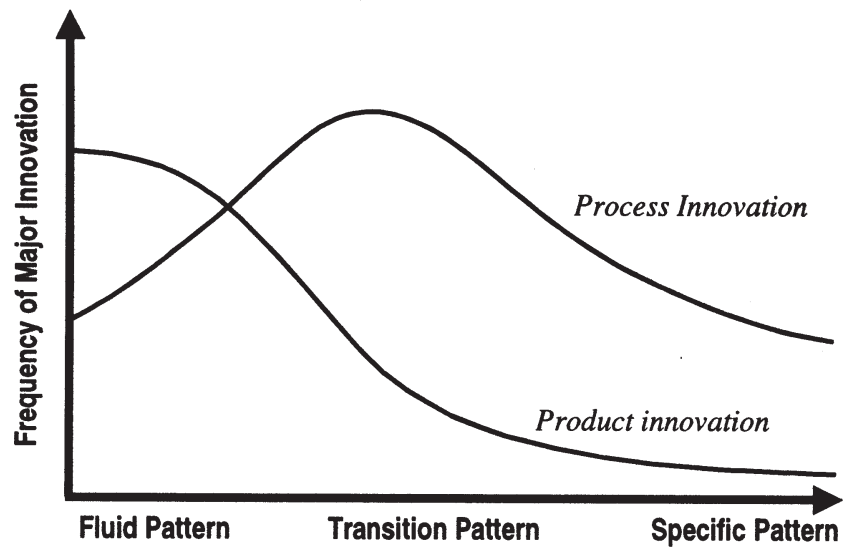

Fig. 2. The "further developed" Utterback \& Abernathy model and patterns of innovation for nonassembled products (Utterback, 1994). The frequency of major innovation in different phases of industrial development over time showing different patterns for product and process innovation.

Three phases in industrial development were identified, classified and named in the original model (later renamed by the authors in parenthesis):

(i) The unco-ordinated (fluid) pattern. Product performance-maximising strategy. Classified on the basis that most innovations are stimulated by market needs.

(ii) The segmental (transitional) pattern. Sales-maximising strategy. Classified on the basis that most innovations are stimulated by technological opportunities. 
(iii) The systemic (specific) pattern. Cost-minimising strategy. Classified on the basis that most innovations are stimulated by production related factors.

The evidence from the empirical testing of the original model seems to confirm the model on an industry level, but the model is discussed by the authors also on a project level and on a company level. A more fruitful approach than discussing whether or when those different models are valid, and whether they are descriptive or prescriptive, is to highlight the important aspects of product and process development that Utterback \& Abernathy put forward in their models, and to use them for further development of the concept and model:

(i) The frequency of major innovations is presented separately for product and process innovation, highlighting the need to distinguish between these two types of development and also the need for a clear definition of those concepts.

(ii) The frequency of major product and process innovations is indirectly related to time, and although it is not explicitly stated in the model, it also relates the total frequency of innovation to time.

(iii) The frequencies of major product and process innovation are presented and discussed together. This focuses attention not only the frequency of each kind of innovation, but also on how they are interrelated.

(iv) It is proposed that different models be applied to Process Industry and Other Manufacturing Industry, recognising the importance of distinguishing between the two categories of industry and the need for clear definitions of those categories.

\section{Product and process development intensity - Two proposed new concepts}

The concept of "frequency of major innovations" (previously called "rate of innovation") used by Utterback \& Abernathy in their models as a measure of innovation, is not well suited for use in industry. The concept of R\&D intensity, however, is well defined and often used when R\&D expenditures are compared between different sectors or groups of industries. It is normally defined as a company's total annual spending on R\&D divided by its total annual turnover, expressed in \% (Statistics Sweden, 1997), and could be used as an alternative yardstick instead of "total innovation frequency".

The need for comparative yardsticks for product and process development that can be related to time has given the incentive to formulate two new concepts in this study. By analogy with the definition of R\&D intensity, it is proposed that "product development intensity" be defined as a company's annual expenditure on product development divided by its total annual expenditure on R\&D, expressed in \%. Similarly, "process development intensity" can be defined as a company's 
annual expenditure on process development divided by its total annual expenditure on $\mathrm{R} \& \mathrm{D}$, expressed in \%. The sum of product development intensity and process development intensity is not necessarily $100 \%$, since there may also be other types of R\&D activities going on in a company. However, such other R\&D activities are often marginal in Process Industry, so the sum of product and process development intensities can probably often be approximately estimated at $100 \%$. These concepts are set out in a more formal manner in Table 1 below.

Table 1. Definitions of concepts related to product and process development intensity in a company.

Total R\&D expenditure $(\$ M)$

R\&D Intensity

Product Development Intensity $\quad=$ [expenditure on Product Development $/$ total R\&D expenditure $] \times 100$

Process Development Intensity $=$ [expenditure on Process Development/total R\&D expenditure $] \times 100$

\section{An Exploratory Survey to R\&D Managers in European Process Industry}

\section{Research approach and methodology}

The results presented in this paper are part of a larger research project on the development of process technology in Process Industry. In this project a survey was conducted among R\&D managers in European Process Industry during 1998 and 1999. It included a lengthy (8-page) questionnaire concerning various aspects of process development. Before the questionnaire was compiled, the new concepts were presented to and individually discussed with eight R\&D managers from companies selected from different sectors of Process Industry in Sweden and Norway, in association with other unstructured interviews regarding other parts of the total research project. The total questionnaire was pilot tested on three R\&D managers before being distributed to 327 R\&D managers in European Process Industry with a focus on Swedish Process Industries. The categorisation of Process Industries, the sample for the survey and the further conduct of the survey are described in Appendix.

\section{Usability of the definitions}

The previously presented definitions were set out right at the beginning of the questionnaire because it was essential that the respondents clearly understood the 
difference between product and process development; this was crucial to obtaining an accurate estimate of the process development share of total $R \& D$. The aim was firstly to ensure that each respondent had carefully read and reflected on this important issue before answering the questionnaire, secondly to test the industrial applicability of the proposed definition. The first question was: Do you consider it important in your company to distinguish between product development and process development? And as a follow-up question: Do you consider the definitions presented above to be operatively useful? The results are presented in Figs. 3(a) and (b).

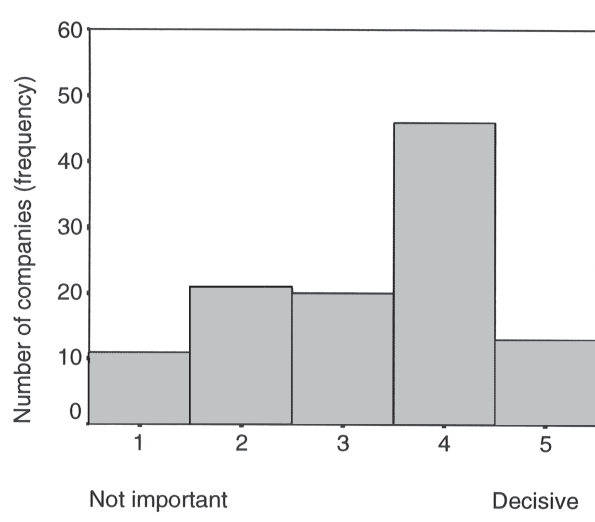

Fig. 3(a). Frequency curves of answers to the question whether it is important to distinguish between product and process development.

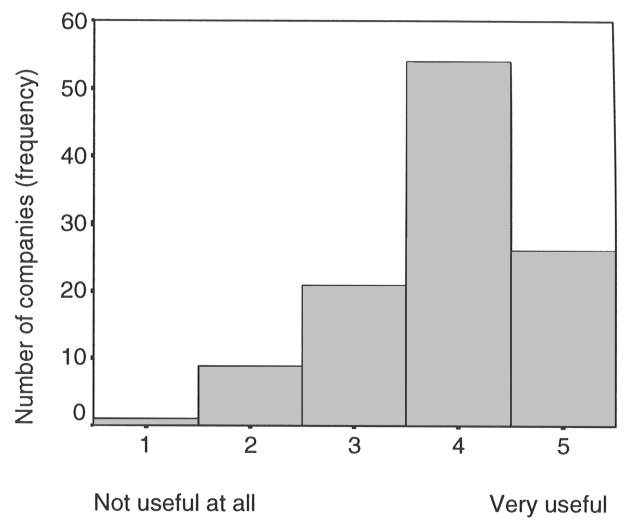

Fig. 3(b). Frequency curves of answers to the question whether the presented definition is operatively useful.

A Chi-Square test of the cross-tabulated distributions (the scales dichotomised into two groups 1-3 and 4-5), shows a significant dependence between the variables $(p<0.05)$. Those who considered it important to distinguish between product and process development also rated the usefulness of the definition higher. The respondents did not show an overwhelming desire to distinguish between product and process development, but there was a better support for the usefulness of the presented definition.

\section{The importance of $R \& D$ and its organisational affiliation}

The respondents were presented with some general questions about future development in their companies. This part started with two simple questions about the importance of R\&D. The first question was: It is often claimed that 
successful research and technical development will be one of the most important competitive factors for successful industrial organisations in the future. Do you share this opinion? The question is certainly a "no-brainer". Agreement with this statement was almost unanimous, 96\%. One might perhaps conclude that an R\&D manager who does not agree with it ought not to be an R\&D manager. This question was however intended merely as a preliminary to a follow-up question about the attitude of top management to R\&D: Does the top management of your company share this opinion? The results showed that $78 \%$ believed so, $16 \%$ did not know, while $6 \%$ believed that top management did not share this opinion.

Since product development was assumed to belong to $R \& D$, a question related to future organisational affiliation of process development was asked: Will process development work in the company in the future belong to the $R \& D$ or Production organisation? Regrettably, the answer "Both" was not given as an alternative in the inquiry, but it was often added and used by the respondents. The results are presented in Table 2 .

Table 2. Future organisational affiliation of process development for different categories of Process Industry.

\begin{tabular}{|c|c|c|c|c|c|c|c|}
\hline & \multicolumn{6}{|c|}{ Classification of Industry Category in this Study } & \\
\cline { 2 - 7 } $\begin{array}{c}\text { Future } \\
\text { Organisational } \\
\text { Affiliation }\end{array}$ & $\begin{array}{c}\text { Mining \& } \\
\text { Mineral } \\
\text { Industry }\end{array}$ & $\begin{array}{c}\text { Food \& } \\
\text { Beverage } \\
\text { Industry }\end{array}$ & $\begin{array}{c}\text { Pulp \& } \\
\text { Paper } \\
\text { Industry }\end{array}$ & $\begin{array}{c}\text { Chemical } \\
\text { Industry }\end{array}$ & $\begin{array}{c}\text { Basic } \\
\text { Metal } \\
\text { Industry }\end{array}$ & $\begin{array}{c}\text { Other Types } \\
\text { of Process } \\
\text { Industry }\end{array}$ & Total \\
\hline R\&D & $72.7 \%$ & $27.8 \%$ & $33.3 \%$ & $77.8 \%$ & $31.8 \%$ & $52.4 \%$ & $50.9 \%$ \\
Production & $27.3 \%$ & $61.1 \%$ & $44.5 \%$ & $14.8 \%$ & $45.5 \%$ & $33.3 \%$ & $36.1 \%$ \\
Both & & $11.1 \%$ & $22.2 \%$ & $7.4 \%$ & $22.7 \%$ & $14.3 \%$ & $13.0 \%$ \\
\hline Total & $100.0 \%$ & $100.0 \%$ & $100.0 \%$ & $100.0 \%$ & $100.0 \%$ & $100.0 \%$ & $100.0 \%$ \\
\hline
\end{tabular}

All categories except Mining \& Mineral Industry used the alternative "both", with the largest figure around $20 \%$ for Pulp \& Paper Industry and Basic Metal Industry. Pulp \& Paper Industry and Basic Metal Industry also show a rather similar pattern for the distribution between the three alternatives. The highest figure for future organisational affiliation to R\&D is Chemical Industry, 77.8\% The second highest figure for future process development affiliation to R\&D is Mining and Mineral Industry, 72.7\%. Food \& Beverage industry shows the highest figure for process development affiliation to production, $61.1 \%$. 


\section{R\&D intensity}

Current R\&D intensities were calculated using the respondents' figures for total company turnover and the figures for company R\&D expenditure. The results are presented in Fig. 4, using box plots where the bold horizontal line in each box shows the median, the distance between the ends of the box the interquartile range, the whiskers the highest and lowest figures, the circles outliers. The arithmetical averages are also shown in parentheses in the text below. It can first of all be noted that most of the values are below $4 \%$ for all companies included in this study. All medians for all categories of industry are below 3\%, and the overall median figure for the total sample is $1.5 \%$.

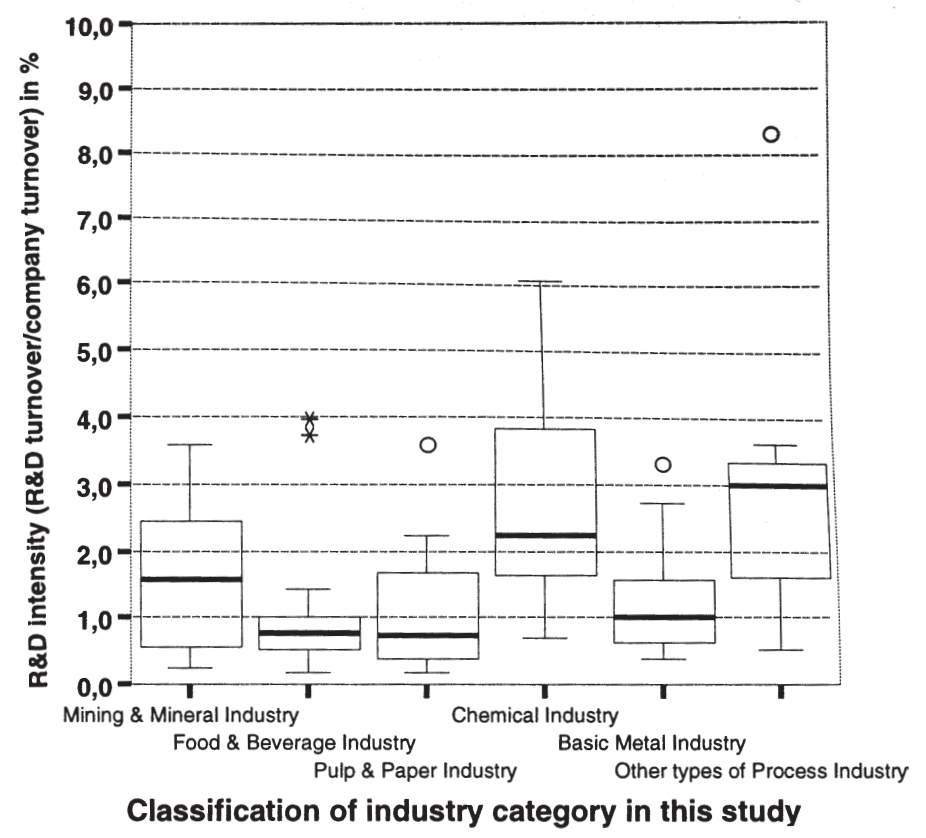

Fig. 4. R\&D intensities for different categories of Process Industry presented as box plots. The bold horizontal line in each box shows the median for the category. The box represents the interquartile range (50\% of all values). The whiskers show the largest and smallest observed values. Circles represent outliers and crosses extremes.

The median figure is highest for Other Types of Process Industry, 3.0\% (4.6\%). The second highest is Chemical Industry 2.2\% (3.0\%), followed by Mining \& Mineral Industry $1.6 \%$ (1.6\%), Basic Metal Industry $1.0 \%$ (1.3\%), Food \& Beverage Industry $0.8 \%(1.2 \%)$, and the lowest is Pulp \& Paper Industry $0.7 \%$ (1.2). The extreme values for Food \& Beverage Industries do not represent 
different types of food industries, but companies belonging to food industry in a specific European country. An ANOVA test shows significant differences between the different categories $(p<0.005)$. A post hoc test with Bonferroni correction shows only significant differences between Food \& Beverage industry and Chemical Industry and further between Chemical Industry and Basic Metal Industry. The overall impression is that there is a considerable spread in the values within each category of Process Industry. For example, the Mining \& Mineral Industry median for R\&D intensity in this study is $1.6 \%$, but the lowest figure is $0.2 \%$ and the highest is $3.6 \%$.

\section{Product and process development intensity}

Process development intensities were given directly by the respondents at the beginning of the questionnaire (they were asked to state the share of total company R\&D spent on process development). The results are presented in Fig. 5, with the same symbols as in Fig. 4.

The median and arithmetical average of process development intensity for the total group of companies in this study are both $40 \%$, with an interquartile range

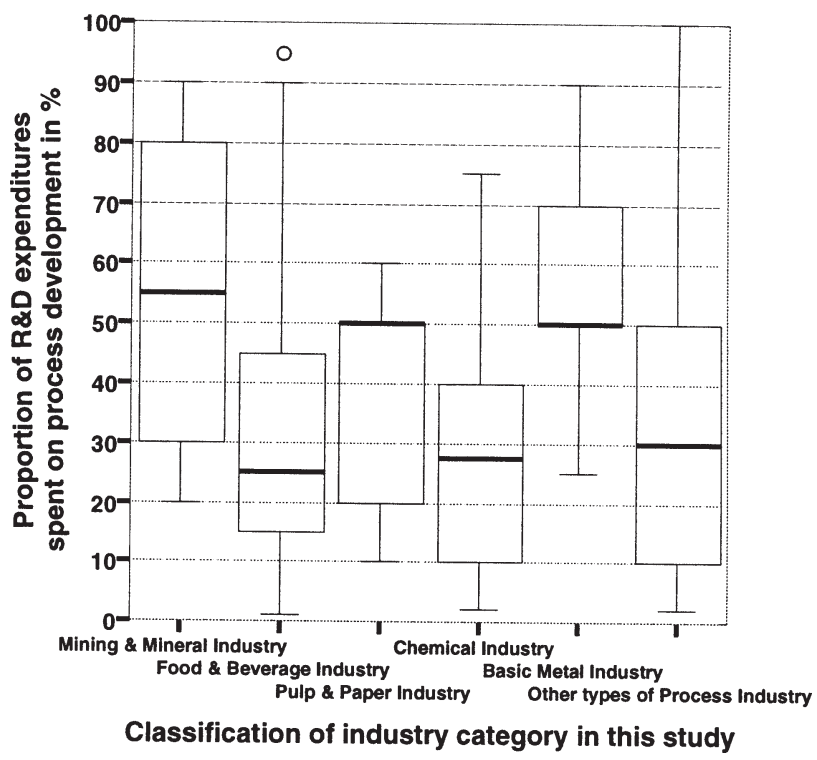

Fig. 5. Process development intensity in different categories of Process Industry, presented as box plots where the bold horizontal line in each box shows the median for the category. The box represents the interquartile range (50\% of all values). The whiskers show the largest and smallest observed values. The circles represent outliers. 
of $30 \%$. It can thus first of all be noted that there is a tremendous spread in the figures for process development intensity for the total group of companies in this study: the process development share of total $\mathrm{R} \& \mathrm{D}$ expenditures ranges from $0 \%$ to $100 \%$. An ANOVA test shows significant differences in process development intensity between the different categories of industry $(p<0.001)$. A post hoc test with Bonferroni correction shows significant differences between two groups.

The first group comprises the three categories with a median figure around $50 \%$. The highest median value is 55\% (mean 55.5\%) for Mining \& Mineral Industry, followed closely by $50.0 \%$ (38.9\%) for Pulp \& Paper Industry and $50.0 \%(57.1 \%)$ for Basic Metal Industry. The other group includes the three other categories with a median close to $30 \%$. This group includes Other Process Industry $30.0 \%$ (36.1\%), Chemical Industry 27.5\% (27.8) and Food \& Beverage Industry $25.0 \%(33.3 \%)$.

No category of Process Industry has closely grouped values, and the spread is very high within each category. As shown in Fig. 5, the Mining \& Mineral Industry has an interquartile range of $54 \%$ (the range where $50 \%$ of all values can be found). For Food \& Beverage Industry the interquartile range is smaller but the range for the lowest and highest value is nearly $100 \%$. The strangelooking boxes with medians at the top or bottom represent groups of companies with a large number of values identical to the median and this quartile. Looking at the figures from an opposite angle using the previously discussed assumption that product and process development intensities add up to approximately $100 \%$, product development intensity is highest in Food \& Beverage Industry at around $75 \%$, compared to Mining \& Mineral Industry where product development is the lowest at around $45 \%$.

\section{Future process development intensity}

As a follow-up question to the question about process development share of total $R \& D$ expenditures (process development intensity), respondents were asked about the future prospects for company process development: "Do you estimate that the process development share of total development work will decrease, not change or increase in your company?" The results are presented in Table 3 below.

The results show an overall trend towards an increasing share of process development in the future. This is very clear, around $80 \%$, for the group including the two categories Mining \& Mineral Industry and Food \& Beverage Industry, but here we also find the two highest figures for a decrease. In other words, change is expected in both directions. The other group comprises the remaining categories, and in this group Chemical Industry has the lowest figure for an expected increase in process development at $53.6 \%$. 
Table 3. Expected change in process development intensity for different categories of Process Industry.

\begin{tabular}{|c|c|c|c|c|c|c|c|}
\hline & \multicolumn{6}{|c|}{ Classification of Industry Category in this Study } & \\
\hline & $\begin{array}{c}\text { Mining \& } \\
\text { Mineral } \\
\text { Industry }\end{array}$ & $\begin{array}{c}\text { Food \& } \\
\text { Beverage } \\
\text { Industry }\end{array}$ & $\begin{array}{c}\text { Pulp \& } \\
\text { Paper } \\
\text { Industry }\end{array}$ & $\begin{array}{l}\text { Chemical } \\
\text { Industry }\end{array}$ & $\begin{array}{c}\text { Basic } \\
\text { Metal } \\
\text { Industry }\end{array}$ & $\begin{array}{c}\text { Other Types } \\
\text { of Process } \\
\text { Industry }\end{array}$ & \\
\hline Decrease & $9.1 \%$ & $11.1 \%$ & & & $4.3 \%$ & $4.3 \%$ & $4.5 \%$ \\
\hline Not change & $9.1 \%$ & $11.1 \%$ & $33.3 \%$ & $46.4 \%$ & $39.1 \%$ & $34.8 \%$ & $32.1 \%$ \\
\hline Increase & $81.8 \%$ & $77.8 \%$ & $66.7 \%$ & $53.6 \%$ & $56.6 \%$ & $60.9 \%$ & $63.4 \%$ \\
\hline Total & $100.0 \%$ & $100.0 \%$ & $100.0 \%$ & $100.0 \%$ & $100.0 \%$ & $100.0 \%$ & $100.0 \%$ \\
\hline
\end{tabular}

\section{Discussion of Research Results}

\section{The need for clear definitions}

Fuzzy definition of R\&D concepts will not only influence the comparison between different categories of $\mathrm{R} \& \mathrm{D}$, but will also influence the comparison of product and process development intensities between companies and comparison of empirical research results with existing theoretical models. The general impression from the literature survey is thus that there is a need for better definitions of the concepts of product and process development, although there is no clear empirical support for this from the study. The weak support for the recommended sharper distinction between product and process development could possibly be attributed to the respondents mistaking this for a recommendation to separate product and process development activities.

On the contrary, it is felt that an integration of product and process development is probably a necessity to reap the fruits of individual but different development activities, as indeed some respondents pointed out in supplementary comments. There was, however, clear support for the usability of the proposed definitions

\section{The organisational aspect of product and process development}

The results from this study indicate three possible options for the future organisational affiliation of process development: the R\&D organisation, the production organisation, or both. The future departmental affiliations may however be less important than the organisation of efficient work processes for process development transcending departmental demarcation lines. Referring to the results from the literature survey, the advantages of locating process development to the R\&D organisation might be to give a good environment for more long-term 
process development activities of a more innovative character. The advantage of locating process development to production might to be to facilitate incremental development by make it easier to transfer results direct to production (Lager, 2000).

The shift from a strict departmental organisation to transfunctional teams managed by project managers for product development is a clear trend in Other Manufacturing Industry (see for example Clark and Fujimoto, 1991). The importance of establishing transfunctional structures and modes of collaboration for process development and production is still relevant, because the departmental organisations will probably survive some time in Process Industry as some sort of organisational backbone even in the future, although the focus will be more on work processes and in this case the "process development process".

\section{R\&D intensity}

R\&D intensity in individual companies, taken as a measure of the importance the company attaches to R\&D, was not the main research question for this study, since these figures are sometimes and to a certain extent available for various sectors of industry from public statistics. The R\&D intensities calculated from the study were however so interesting that they deserved some attention. The average R\&D intensities for different categories of industry are interesting for companies to compare with, but the dispersion of $R \& D$ intensity within each category (often not available in public statistics) is even more so. The explanation for the wide dispersion of R\&D intensity within each category may be that the breakdown into only six types of Process Industry is too coarse. Another explanation is that such large differences actually exist even within finer categories (sub-sectors). The individual cases in this study appear to support the latter explanation. There may probably also be other factors influencing R\&D intensity within the same category, such as different corporate and R\&D strategies, as well as company-specific fluctuations in $R \& D$ expenditures which may, but not necessarily must, have a cyclic pattern.

It must always be remembered that $R \& D$ intensity is heavily influenced by fluctuations in a company's annual turnover. The $R \& D$ intensity can also be illusory, since a large company with low R\&D intensity but with a high turnover still spends a sizeable amount on R\&D in absolute figures, which will be reflected in its $R \& D$ organisation and its innovative capacity. On the other hand, a small company with a high $R \& D$ intensity but a low turnover cannot undertake large development projects. This suggests that $R \& D$ expenditures should also be considered in terms of absolute figures. 
Because the public statistics use a different classification system, and the sample is taken from a different population, a strict comparison is not possible with public statistics. Comparing with the results from the study, one can only say that the figures agree fairly well with Swedish statistics for some industries, but differ substantially for others. One may ask whether figures from public annual statistics for different sectors of industry could, or should, be used as a guideline for individual companies. The results from this study show that a company must be careful when comparing its $R \& D$ intensity with published statistics for its category, because there seems to be a large spread of figures within each sector. A comparison of company $R \& D$ intensity with selected competitors would appear to be more relevant. Each company should carefully consider its past and future figures for R\&D intensity (Cooper, 1988), but it must also be remembered that the amount of money spent on R\&D is not the only important parameter. How well the money is used is another matter. Nevertheless, it is felt that $R \& D$ intensity is an important yardstick for companies provided that it is used cautiously, it is monitored over a longer period of time and it is compared with selected competitors.

\section{Present and future product and process development intensities}

In this study, $40 \%$ of total company R\&D expenditure, as an arithmetical average for all companies, was spent on process development and over $60 \%$ of the companies expected this figure to increase in the future and very few foresaw a decrease. The answer to the question of whether process development is important in Process Industry is on the whole affirmative, and there is a clear indication that it will remain so in the future.

If we assume that all other company $R \& D$ resources are spent on product development (which however is not certain in the light of the previous discussions and definitions), the complementary figure for product development intensity is $60 \%$. This figure indicates that the importance of product development in this group of companies is currently higher than, or at least as high as, the importance of process development. The results show a remarkably high dispersion within each category of industry. This may be an indication that there are more factors influencing the relation between product and process development intensities than just the type of industry, which was selected as a discriminating variable for the data analysis. The primary reason for selecting type of industry as a variable is that it refers to industrial reality and is related to the competitive environment in which each industry operates.

The results clearly show that an increase in process development intensity is expected in the future by most of the companies in this study. One explanation 
of this rather interesting trend could be that the emphasis on product development during the past ten years has resulted in too little attention being paid to process development, even to the point of neglect, and that the time has now come to focus more on cost reduction. Another explanation could be that if spending on product development and new products has increased, that very fact will tend to encourage process development. The explanation of the fact that two groups of Process Industries show slightly different patterns for the expected increase of process development intensity might be that companies in the Mining \& Mineral Industry often tend to be commodity producers with a need for more process development, while the Food \& Beverage Industry currently has the lowest process development intensity, which possibly needs to be increased.

One explanation of the spread in the results could be that individual companies are currently in different phases of product and process development (which has also been pointed out by respondents in the study) and that the relationship between product and process development does not necessarily follow a generic homogeneous pattern for a sector of industry as a whole, but a company-specific pattern which may or may not be cyclic in nature. Another explanation could be that the different companies have different customers whose needs prompt them to adopt different overall corporate strategies. This might require different emphasis on R\&D and consequently on R\&D intensity. Different R\&D strategies and variations in $R \& D$ intensity could then emerge as different patterns for both product and process development intensity.

\section{Comparison of research results with the Utterback \& Abernathy models}

The further developed Utterback \& Abernathy model gives a relationship between the frequency of major product and process innovation for non-assembled products in different stages of industry development, see Fig. 2. They discuss the model on industry, company and product category levels. In the initial Fluid Pattern, product innovation is twice as frequent as process innovation; in the following Transition Pattern, process innovation is at least twice as frequent as product innovation; and in the final Specific Pattern, process innovation is about five times as frequent as product innovation (Utterback, 1994).

If one assumes that most of the industries and companies in this study are "mature", they should according to the Utterback \& Abernathy classification be in their last phase of industrial development, follow the Specific Pattern and have much more process development than product development. While one cannot claim that the concept of "frequency of major innovations" equals the concepts of "product and process development intensity", it is as close as one can get to a comparison of the theoretical model with industrial reality. If on the other hand 
the companies are not considered as "mature", or if different companies are in development phases corresponding to the Utterback \& Abernathy "new waves", the results might fit the models, but then on the other hand all possible result fit the models, and the models are not testable.

One could also argue that the expected increase in process development share of total R\&D resources could fit the Utterback \& Abernathy model, with process development becoming progressively more important than product development in mature industries making non-assembled products. But on the other hand, product development intensity is higher than process development intensity in the total group of companies in this study. If we look at the individual cases in the study, there do not seem to be patterns that can be explained by different waves of development, and the conclusion is thus that the results from this study do not support the models. Other studies, e.g. Pisano (1997) and Bower \& Keogh (1996) have also observed this lack of fit with empirical data from industry.

\section{Validity and reliability of research results}

The construct validity of the research results must be considered to be high because the respondents were R\&D managers familiar with the type of questions in the questionnaire. The definitions of product and process development were clearly presented at the outset, and the follow-up questions regarding their usefulness laid a good foundation for understanding before the second question about the proportion of process development was posed.

The reliability of these figures must also be considered high because they are of a kind that most R\&D managers have available. The R\&D intensities were calculated from company background data and must be considered very reliable.

\section{Implications for Industry and Further Research}

\section{Implications for industry}

The concept of R\&D intensity has been used for a long time in public statistics, but deserves more attention than it receives from industry. The complementary use of the proposed new concepts of product and process development intensity will put more focus on how R\&D resources are allocated and how congruent this is with company $R \& D$ strategy. Trend curves over time for company $R \& D$ intensity, together with trend curves for product and process development intensity, will provide interesting background information for in-house discussions - even more so if the data are further supplemented with data from selected competitors. A clearer distinction between product and process development could also be 
supplemented with further classification of these activities into different categories of product and process development. Such a classification of both product and process development according to the newness of products and processes and how the resources are allocated is also recommended, see for example Booz, Allen \& Hamilton (1982), Griffin \& Page (1996), Lager (2002). Since a company's progress is understood by looking back but has to be planned ahead, using the figures for the above indicators from the past, present and future can be an interesting point of departure for more factually based discussions of company R\&D strategy.

\section{Further research}

The companies selected for this study are all from Process Industry, but the research questions are also relevant to other categories of industry. Gold points out that it is difficult to draw conclusions from studying large samples including a wide spectrum of different industries because those results will invariably represent the dubious average net results of a wide range of developments and outcomes under different circumstances (Gold, 1989). It might thus be interesting to follow up the research results from this exploratory study by taking individual companies or small groups of similar companies and subjecting them to explanatory case studies with a retrospective and longitudinal research approach. To be able to compare research results from different studies, there is a need for better defined concepts not only for product and process development but also for R\&D in general.

Further research is needed to develop better and more explanatory models for product and process development. In the light of the research results from this exploratory study, industrial reality seems to be more complex than present models are capable of explaining. In a further search for better models it is important first of all to decide at which level of analysis we are aiming.

There is certainly a difference in trying to develop industry-level models for a whole group like Process Industry, compared with company-level models that can be applied to individual companies. If we select the company level, we must also be clear about whether the models are supposed to be descriptive or prescriptive. The difference is monumental, because all we are saying in the first case is that the models should fit existing company data, whereas if the models are intended to be prescriptive, companies should also be able to use them as guidelines for further action.

It is always advisable to begin by trying to describe reality, and we should then also start to translate development activities into the language of variables and functions. Using the previously introduced new concepts and relating them 
to time can be one approach, i.e. looking for empirical company data and studying the patterns that emerge. There are a number of variables other than time that might affect a company's product and process development intensity and we could tentatively categorise them into variables that are company-specific and variables that are of a more contextual nature.

Process Development Intensity $=f(a, b, c, \ldots)$.

Product Development Intensity $=f(x, y, z, \ldots)$.

\section{Conclusions}

The share of total company resources spent on $R \& D$, as reflected in $R \& D$ intensity, is certainly a matter of strategic importance. The figures for R\&D intensity naturally differ between different categories of Process Industry, but a wide dispersion of the figures has also been observed within each category. This indicates that companies ought to be careful about comparing their R\&D intensities with average sectorial figures from public statistics, and that comparison with selected competitors appears to be more relevant.

In the choice of future organisational affiliation of company process development the three options - R\&D, production, or both - are all possible, favoured differently by different sectorial affiliations. It is suggested that an analysis of the nature of the company process development should, however, be a better guideline for this choice than the sectorial affiliation. When the character of process development work is both of a short-term incremental character and of a long-term and more innovative character it is suggested that the departmental location should be in both places. The question of the organsisational affiliation of process development must not however be confused with the necessity of organising transfunctional development teams including both $R \& D$ and production.

Company R\&D intensity sets the limit for total available resources for product and process development and other complementary R\&D activities. The selected division of resources between product and process development is reflected in the new suggested concepts of product and process development intensity. In this study, $40 \%$ of total company R\&D resources were spent on process development; over $60 \%$ of the companies expected that figure to increase in the future, while very few foresaw a decrease. The answer to the question of whether process development is important in Process Industry is on the whole affirmative, and there is a clear indication that it will remain so in the future. If we assume that all other company $\mathrm{R} \& \mathrm{D}$ resources are spent on product development, the complementary figure for product development intensity is $60 \%$. This figure indicates that the importance of product development in this group of companies 
is at present rated higher than, or at least as high as, that of process development.

It is generally perceived in this study (but with no empirical support), that concepts and definitions of different categories of $\mathrm{R} \& \mathrm{D}$, and product and process development in particular, need to be improved. The results from this study do not fit the most widely used model for the relation between product and process development. Improved models are needed to describe and explain how company $\mathrm{R} \& \mathrm{D}$ resources are and should be allocated.

Product and process development intensities can be looked upon as an aggregated measure of individual development efforts by a company, and it is thus argued that product and process development intensities are also of overall company strategic importance.

\section{Acknowledgements}

This work has been partly financed by the Kempe Foundations; their financial support is gratefully acknowledged. Thanks are due to Professor Sven-Åke Hörte for encouraging support and to Gunilla Bergdahl for research assistance. Sincere thanks to all companies who participated in the interviews and the survey, and to other persons who helped to improve the quality of this paper. Special thanks to anonymous referees.

\section{Appendix: The Sample and The Survey}

\section{Process Industry}

Companies are often grouped together in clusters of similar types of industries producing similar types of products and using similar production processes. The previously presented intensional definition of Process Industry has been used to select clusters of industries for an extensional definition of Process Industry in this study, using the NACE codes for classification of industries in the European Community (NACE Rev., 1996). Industries that are often grouped into sectors, here proposed to be included in Process Industry, have been selected from the NACE system and clustered for this study in six categories, as Mining \& Mineral Industry, Food \& Beverage Industry, Pulp \& Paper Industry, Chemical Industry, Basic Metal Industry, and Other Process Industry. Those groups of industries can be broken down in more detail into sub-groups. Chemical Industry, for example, can be further divided into Paint Industry, Industry for Basic Chemicals, etc. 


\section{The sample and the sample frame}

The total sample was 337 companies from European Process Industry focusing on Swedish industry. The sample was not a simple random sample but consisted of industries selected according to the following criteria:

\section{Type of industry}

Process Industries were selected according to the previously presented definition. The types of industries were selected using existing statistical codes for European Industry (NACE). Industries from different sectors have been clustered together: Mining \& Mineral Industry (NACE codes 13, 14 \& 26); Food \& Beverage Industry (NACE code 15); Pulp \& Paper Industry (NACE code 21); Chemical Industry - including petrochemical, plastic and rubber but not pharmaceutical (NACE codes 23, 24 \& 25); Basic Metal Industry (NACE code 27); Other Process Industry (NACE codes 28, 37, 40, $41 \& 24.4$ plus some other industries connected to Process Industry).

\section{Geographical location}

The total Swedish sample is 109 companies. A fairly large number of industries from other Nordic countries were also selected (Norway, Finland and Denmark). Total sample of Nordic countries other than Sweden: 80 companies. From the rest of Europe we selected a smaller sample of industries (Germany, the United Kingdom, France, the Netherlands, Belgium, Italy, Austria and Switzerland). Total sample of European countries other than Nordic countries: 148.

\section{Size of industry}

The firms contacted had at least 200 employees, often more than 500 employees and in many cases many more.

\section{Innovation intensity}

Some parts of the industry sectors presented above were excluded from the sample because of our estimates that the innovation intensity for this group of industries was too low. Thus, meat production and concrete production, for example, were excluded from the survey. 


\section{The conduct of the survey}

The questionnaire was sent out to R\&D managers in the respective companies. All questionnaires were sent to a specific person whom we had identified as the right respondent in the organisation. For practical reasons, the method of conducting the survey in Sweden differed from the one used in the rest of Europe. The Swedish survey was carried out according to the following scheme: telephone contact with companies, checking the data and confirming participation - mailing the questionnaire - telefax reminders - telephone reminder - new telephone reminder - final telefax reminder. The scheme for the Nordic and European surveys was: mailing the questionnaire - new mailings after new information (new contact persons or address) — telefax reminder — final telefax reminder.

\section{Response rate}

\begin{tabular}{lccc}
\hline \hline & Sweden & Other Nordic counties & Other European countries \\
\hline Number contacted & 109 & & \\
Number of mailings & 99 & 80 & 148 \\
Number of responses & 78 & 18 & 16 \\
Response rate & $72 \%$ & $23 \%$ & $11 \%$ \\
\hline \hline
\end{tabular}

The response rate is very good for Sweden, considering that the total number of respondents including those who declined to participate on the telephone before the mailing is included in the sample. For some sectors nearly all industries were included in the Swedish sample, making it close to a census for those groups. The response rate dropped dramatically for the rest of the sample because of the different design of the survey.

\section{References}

Balachandra, R. \& Friar, J.H. (1997) Factors for success in R\&D projects and new product innovation: A contextual framework. IEEE Transactions on Engineering Management, 44(3), 276-287

Booz, Allen \& Hamilton (1982) New Products Management of the 1980s. Booz, Allen \& Hamilton Inc.

Bower, D.J. \& Keogh, W. (1996) Changing patterns of innovation in a process-dominated industry. International Journal of Technology Management, 12(2), 209-220 
Chronéer, D. (1999) Customer-oriented trend in steel and pulp/paper industries? Department of Business Administration and Social Science, Division of Industrial Organisation, Luleå University of Technology, Licentiate thesis, 46

Clark, K.B. \& Fujimoto, T. (1991) Product Development Performance, Harvard Business School

Cobbenhagen, J., den Hertog, F. \& Philips, G. (1990) Management of innovation in the processing industry: a theoretical framework. In New Explorations in the Economics of technological change, ed. C. Freeman and L. Soete, 55-72, London: Printer Publishers

Cooper, R.G. (1988) Winning at New Products. London: Kogan Page

Cooper, R.G. \& Kleinschmidt, E.J. (1995) Benchmarking the firm's critical success factors in new product development. Journal of Product Innovation Management, 12(5), 374-391

Gold, B. (1987) Approaches to accelerating product and process development. Journal of Product Innovation Management, 4(2), 81-86

(1989) Some key problems in evaluating R\&D performance. Journal of Engineering and Technology Management, 6, 59-70

Griffin, A. \& Page, A.L. (1996) PDMA Success measurement project: Recommended measures for product development success and failure. Journal of Product Innovation Management, 13, 478-496

Hutcheson, P., Pearson, A.W. \& Ball, D.F. (1996) Sources of technical innovation in the network of companies providing chemical process plant and equipment. Research Policy, 25, 25-41

Lager, T. (2000) A new conceptual model for the development of process technology in process industry. International Journal of Innovation Management, 4(3), 319-346

(2002) A structural analysis of process development in Process Industry. A new classification system for strategic project selection and portfolio balancing. $R \& D$ Management, 32(1), 87-95

Lager, T. \& Hörte, S.Å. (2002) Success factors for improvement and innovation of process technology in process industry. Integrated Manufacturing Systems, 13(3), $158-164$

Leonard-Barton, D. (1992) The factory as a learning laboratory. Sloan Management Review/Fall, 23-38

Linn R.A. (1984) Product development in the chemical industry: A description of a maturing business. Journal of Product Innovation Management, 2, 116-128

NACE Rev. 1 (1996) Statistical Classification of Economic Activities in the European Community. Luxembourg: Office for Official Publications of the European Communities

OECD (1997) Oslo Manual. Paris: OECD

Pisano, G. P. (1997) The Development Factory. Boston: Harvard Business School Press Research and Development in the Business Enterprise Sector (1997), Statistics Sweden, Official statistics of Sweden, Publication services, Örebro, Sweden 
Skinner, W. (1992) Precious jewels: Companies that achieve competitive advantage from process innovation. International Journal of Technology Management, 7(1/2/3), 41- 48

Stobaugh, R. (1988) Innovation and Competition. The Global Management of Petrochemical Products. Harvard Business School Press

Tottie, M. \& Lager, T. (1995) QFD - Linking the customer to the product development process as part of the TQM concept. $R \& D$ Management, 25(3) 257-267

Utterback, J.M. \& Abernathy W.J. (1975) A dynamic model of process and product innovation. Omega, 3(6), 639-655

Utterback, J.M. (1994) Mastering the Dynamics of Innovation. Harvard Business School Press

Yoshida, S. (1998) Development and innovation in the Japanese chemical industry. International Journal of Technology Management, 15(6/7), 568-585 
Copyright $\odot 2002$ EBSCO Publishing 